\title{
Research Article \\ Effect of Chloride Ion on Free Nitrite Ion in Cement
}

\author{
Xiangwei Xing (iD, Junzhe Liu $\mathbb{D}$, Yanhua Dai, Mengna Yang, and Yushun Li
}

Faculty of Architectural, Civil Engineering and Environment, Ningbo University, Ningbo 315211, China

Correspondence should be addressed to Junzhe Liu; liujunzhe@nbu.edu.cn

Received 17 January 2018; Revised 2 April 2018; Accepted 10 April 2018; Published 2 July 2018

Academic Editor: Flavio Deflorian

Copyright (C) 2018 Xiangwei Xing et al. This is an open access article distributed under the Creative Commons Attribution License, which permits unrestricted use, distribution, and reproduction in any medium, provided the original work is properly cited.

\begin{abstract}
This was an experiment in which chloride was externally permeated into cement paste. The influence of $\mathrm{Cl}^{-}$on the content and distribution of free-form $\mathrm{NO}_{2}{ }^{-}$in the cement paste was researched using the chemical quantitative analysis method. The action mechanism was investigated by the micro-means of X-ray diffraction (XRD) and scanning electron microscopy (SEM). The results show that the physical competitive adsorption of $\mathrm{Cl}^{-}$with $\mathrm{NO}_{2}{ }^{-}$on $\mathrm{C}-\mathrm{S}-\mathrm{H}$ and the chemical substitution of $\mathrm{Cl}^{-}$to $\mathrm{NO}_{2}-\mathrm{AFm} \mathrm{caused}^{-}$ more free-form $\mathrm{NO}_{2}{ }^{-}$in the cement paste. In the cement paste with chloride salt erosion, the $\mathrm{NO}_{2}{ }^{-}$concentration in the erosion surface was the lowest, and the $\mathrm{NO}_{2}^{-}$concentration reached the highest value at $10 \mathrm{~mm}$ from the erosion surface. The concentration decreased gradually with the depth from the erosion surface.
\end{abstract}

\section{Introduction}

Corrosion of rebar is a very important factor that affects the durability of reinforced concrete structures. This has great impact on the durability of concrete structures. There are varieties of methods of repair for steel corrosion used in China and in other parts of the world [1-3], such as concrete coating, concrete realkalization, cathodic protection, and electrochemical chlorine removal methods. Through a comprehensive comparison of the commonly used methods, findings showed that the most simple and effective way to improve durability is to mix steel rust inhibitor into the concrete. Not only does this effectively slow the corrosion rate of steel and delay the onset of rebar corrosion, but also it solves the problem of the repassivation of the steel.

Nitrite is the best corrosion inhibitor. It is the one used most widely and in the largest quantities [4-6]. Concrete mixed with nitrite rust inhibitor is used to protect the steel in the reinforced concrete. There are many reports of use of this method at home and in other countries [7-12]. However, at present, nitrite rust inhibitors are mainly used to evaluate corrosion inhibition mechanisms and the corrosion inhibition effects of steel bars in concrete structures [13-16].

There is a small amount of literature on binding, decomposition of nitrite, and the influencing factors in cement paste. After mixing nitrite rust inhibitor into the concrete structure, $\mathrm{NO}_{2}{ }^{-}$in the structure generally exists in two forms: one is free-form NO2- that is free to move in pore fluids and the other is a hardened $\mathrm{NO}_{2}{ }^{-}$bound by cement hydration products $[10,11]$. The binding $\mathrm{NO}_{2}$ can be divided into two types, according to curing mechanism: the chemical reaction of the solid state ions and the hydration products by physical adsorption of the binding state of the solid state ions. The internal content of free-form $\mathrm{NO}_{2}{ }^{-}$in concrete will directly affect the final rust inhibition effect.

On the other hand, two approaches are generally used to study steel corrosion in concrete: the use of simulated pore solution and the use of actual concrete or mortar. The use of electrolytes that mimic pore solutions facilitates control of the many parameters that influence rebar corrosion. This was the approach chosen for the present investigation. By contrast, the use of cement paste is more intuitive and more accurately reveals the role of the free-form $\mathrm{NO}_{2}{ }^{-}$reaction mechanism.

In summary, the characteristics and influencing factors on the concentration of $\mathrm{NO}_{2}{ }^{-}$in cement paste need to be further explored. In particular, the influence and action principle of $\mathrm{Cl}^{-}$on the free-form $\mathrm{NO}_{2}{ }^{-}$concentration and its distribution are not yet clear [17-19].

In this paper, the introduction of $\mathrm{Cl}^{-}$by external infiltration of chloride salt and the effects of $\mathrm{Cl}^{-}$erosion on the free-form $\mathrm{NO}_{2}{ }^{-}$concentration in cement paste and its microscopic mechanism were studied by means of chemical quantitative analysis combined with X-ray diffraction (XRD) and scanning electron microscopy (SEM), in order to 
TABLE 1: Chemical composition and physical characteristics of ordinary Portland cement.

\begin{tabular}{lc}
\hline Item & Cement \\
\hline Composition (mass \% as oxide) & \\
Calcium oxide (Cano) & 62.24 \\
Silica $\left(\mathrm{SiO}_{2}\right)$ & 20.89 \\
Alumina $\left(\mathrm{Al}_{2} \mathrm{O}_{3}\right)$ & 5.44 \\
Iron Oxide $\left(\mathrm{Fe}_{2} \mathrm{O}_{3}\right)$ & 3.96 \\
Magnesium oxide $(\mathrm{MgO})$ & 1.71 \\
Sulfur trioxide $\left(\mathrm{SO}_{3}\right)$ & 2.65 \\
Physical characteristics & \\
Initial setting time (min) & 160 \\
final setting time (min) & 280 \\
Compressive strength $(\mathrm{MPa})$ & $25.6(3 \mathrm{~d}) 48.5(28 \mathrm{~d})$ \\
Flexural strength $(\mathrm{MPa})$ & $5.12(3 \mathrm{~d}) 7.05(28 \mathrm{~d})$ \\
\hline
\end{tabular}

improve the durability and service life of China's reinforced concrete structures and to provide a theoretical basis for the approaches.

\section{Experimental Program}

2.1. Materials and Specimens. For this research, type I ordinary Portland 42.5 cement, made by the Ningbo Conch Cement Co. Ltd., Zhejiang, was used as paste component. The chemical composition and physical properties of the cement are listed in Table 1.

Distilled water was used in the fabrication of concrete mixtures; $\mathrm{Cl}^{-}$and $\mathrm{NO}_{2}{ }^{-}$were obtained from $\mathrm{NaCl}$ analytical reagent (AR) and $\mathrm{NaNO}_{2}$ analytical reagent (AR), respectively. The tested concrete types were $40 \mathrm{~mm} \times 40 \mathrm{~mm} \times$ $160 \mathrm{~mm}$ rectangular specimens, having cement pastes of three water-to-cement ratios of $0.30,0.40$, and 0.50 .

After demolding, the specimens were cured in a curing room for 28 days. Prior to environmental conditioning, only one surface of concrete was allowed to be penetrated by nitrite solution. The other surfaces were coated with epoxy resin. This was to realize one-dimensional diffusion. The cement paste specimens were separated into two groups representing different exposure conditions: test group (including A-C group, sodium chloride solution containing $2.0 \%$ chloride attack) and control group (including Ac-Cc group, soaked in aqueous solution). More details of the experimental scenarios for these two groups of specimens are given in Table 2. These were removed after 7 days of curing, dried naturally in the shade and sliced at $1 \mathrm{~cm}$ intervals.

\subsection{Specimen Sampling Method}

(1) Determination of Free-Form $\mathrm{NO}_{2}{ }^{-}$in Cement Paste. The sliced cement paste specimen was ground into powder and put into standard square hole stone sieves with apertures of $0.6 \mathrm{~mm}, 0.3 \mathrm{~mm}, 0.15 \mathrm{~mm}$, and $0.075 \mathrm{~mm}$. The sieve was vibrated on a vibrating screen machine. The $0.075 \mathrm{~mm}$ filter powder was then put into a dry box for drying. $1 \mathrm{~g}$ dry powder was put into a conical flask containing $100 \mathrm{ml}$ of water and then placed in a water bath pot. It was heated at a constant temperature of $60^{\circ} \mathrm{C}$, while being agitated with a glass rod for $10 \mathrm{~min}$. The flask was shaken in an air shaker and centrifuged for $10 \mathrm{~min}$. $1 \mathrm{ml}$ of the soak solution diluted 500 times was used to obtain spare extract. Finally, the "water qualitydetermination of nitrogen (nitrite) - spectrophotometric method" (GBT-7493-1987VYD) was used to determine the concentration of free-form $\mathrm{NO}_{2}{ }^{-}$in the samples.

(2) X-Ray Diffraction Analysis. The specimens after curing, soaking, and drying were ground with a mortar and passed through a hole of a $0.3 \mathrm{~mm}$ sieve to achieve a particle size of less than $0.3 \mathrm{~mm}$ powder. They were then dried for $24 \mathrm{~h}$ in an oven at $60 \pm 5^{\circ} \mathrm{C}$. After cooling, the powder was placed in a small plastic sample bag and sealed. The concrete paste specimens were then completed for sampling. The prepared samples were prepared for phase analysis and quantitative analysis by using a D8 ADVANCE X-ray diffractometer manufactured by Bruker AXS.

(3) Scanning Electron Microscopy Analysis. After a time the curing cement mortar samples were removed from the curing room. Then a small hammer was used to knock the samples gently into $10 \mathrm{~mm}$ square pieces. An amount of the fragments was dried for $24 \mathrm{~h}$ in the oven at $60 \pm 5^{\circ} \mathrm{C}$. After cooling these were placed and sealed in plastic sample bags. Scanning for structure took place using a SU-70 field emission scanning electron microscope.

\section{Results and Discussion}

3.1. Effect of Erosion $\mathrm{Cl}$ Concentration on Free-Form $\mathrm{NO}_{2}{ }^{-}$ Concentration. The combination of ions in cement generally has two forms: one is the result of a chemical reaction between $\mathrm{C}_{3} \mathrm{~A}$ and other hydration products in the cement. When $\mathrm{Cl}^{-}$and $\mathrm{NO}_{2}^{-}$exist in the cement paste, $\mathrm{Cl}^{-}$will react with AFm to form Friedel's salt, and $\mathrm{NO}_{2}{ }^{-}$will react with AFm to form $\mathrm{NO}_{2}-\mathrm{AFm}$. Another bound form is when the ions are physically adsorbed into the surface of a hydration product, such as calcium silicate hydrate gel C-S-H [20-23].

Figure 1 is a contrast graph: It shows the free-form $\mathrm{NO}_{2}{ }^{-}$concentration of cement paste specimens with $0.5 \%$, $1.0 \%, 1.5 \%$, and $2.0 \% \mathrm{NO}_{2}{ }^{-}$in water-to-cement ratio of 0.4 , immersed in $2.0 \% \mathrm{NaCl}$ solution and aqueous solution, respectively. The cement paste specimens with a watercement ratio of 0.4 and with $0.5 \%, 1.0 \%, 1.5 \%$, and $2.0 \% \mathrm{NO}_{2}{ }^{-}$ were immersed in $2 \% \mathrm{NaCl}$ solution and aqueous solution. Figure 1 shows the internal free-form of the $\mathrm{NO}_{2}{ }^{-}$concentration contrast curve. It can be seen from Figure 1 that when the same cement paste test piece is immersed in the chloride salt solution the internal free-form $\mathrm{NO}_{2}{ }^{-}$concentration is higher than that in the aqueous solution.

Figures 2 and 3 are X-ray diffraction contrast charts for cement paste specimens with $1.0 \%$ and $2.0 \% \mathrm{NO}_{2}{ }^{-}$mixed in $2.0 \% \mathrm{NaCl}$ solution and aqueous solution for 7 days, respectively. Figure 2 shows that $\mathrm{NO}_{2}{ }^{-} \mathrm{AFm}$ was produced under the condition of natural curing with cement paste containing $1.0 \%$ and $2.0 \% \mathrm{NO}_{2}{ }^{-}$, respectively. After soaking 
TABLE 2: Mix proportions of cement paste specimens.

\begin{tabular}{|c|c|c|c|c|c|}
\hline $\begin{array}{l}\text { specimens } \\
\text { number } \\
\text { (Test group) }\end{array}$ & Water- cement ratio & $\mathrm{NO}_{2}^{-}$Volume & $\begin{array}{c}\text { specimens } \\
\text { number } \\
\text { (Control group) }\end{array}$ & Water-cement ratio & $\mathrm{NO}_{2}{ }^{-}$Volume \\
\hline A-0 & 0.3 & 0 & Ac- 0 & 0.3 & 0 \\
\hline A-1 & 0.3 & $0.5 \%$ & Ac-1 & 0.3 & $0.5 \%$ \\
\hline A-2 & 0.3 & $1.0 \%$ & Ac-2 & 0.3 & $1.0 \%$ \\
\hline A-3 & 0.3 & $1.5 \%$ & Ac-3 & 0.3 & $1.5 \%$ \\
\hline A- 4 & 0.3 & $2.0 \%$ & Ac- 4 & 0.3 & $2.0 \%$ \\
\hline B-0 & 0.4 & 0 & $\mathrm{Bc}-0$ & 0.4 & 0 \\
\hline B-1 & 0.4 & $0.5 \%$ & $\mathrm{Bc}-1$ & 0.4 & $0.5 \%$ \\
\hline B-2 & 0.4 & $1.0 \%$ & Bc-2 & 0.4 & $1.0 \%$ \\
\hline B-3 & 0.4 & $1.5 \%$ & $\mathrm{Bc}-3$ & 0.4 & $1.5 \%$ \\
\hline B-4 & 0.4 & $2.0 \%$ & $\mathrm{Bc}-4$ & 0.4 & $2.0 \%$ \\
\hline $\mathrm{C}-0$ & 0.5 & 0 & $\mathrm{Cc}-0$ & 0.5 & 0 \\
\hline C-1 & 0.5 & $0.5 \%$ & $\mathrm{Cc}-1$ & 0.5 & $0.5 \%$ \\
\hline $\mathrm{C}-2$ & 0.5 & $1.0 \%$ & $\mathrm{Cc}-2$ & 0.5 & $1.0 \%$ \\
\hline C-3 & 0.5 & $1.5 \%$ & $\mathrm{Cc}-3$ & 0.5 & $1.5 \%$ \\
\hline C-4 & 0.5 & $2.0 \%$ & Cc- 4 & 0.5 & $2.0 \%$ \\
\hline
\end{tabular}

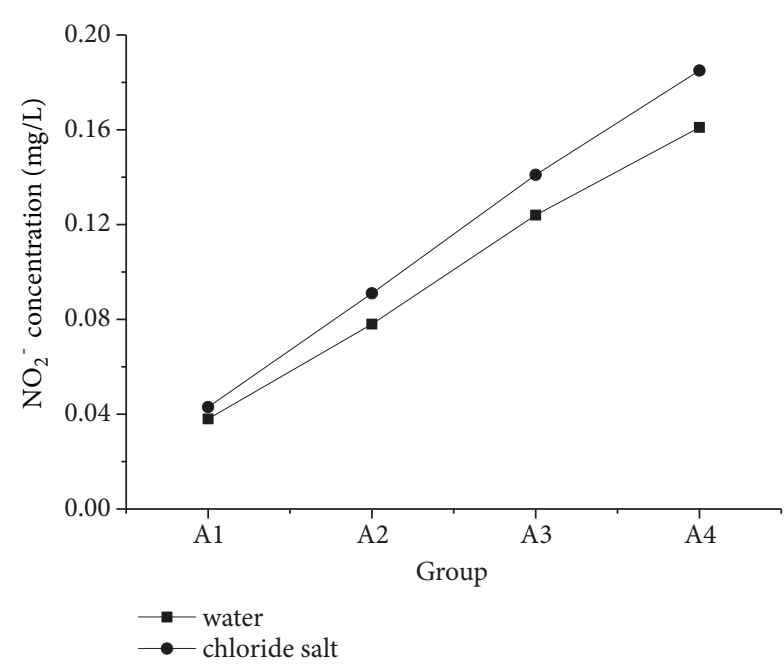

FIGURE 1: Concentration comparison of free-form $\mathrm{NO}_{2}{ }^{-}$.

in an aqueous solution, the value of the $\mathrm{NO}_{2}{ }^{-} \mathrm{AFm}$ diffraction peak of hydration products basically disappeared. It is possible that water molecules had infiltrated to lower the $\mathrm{pH}$, causing them to break down or change to other substances. Friedel's salt diffraction peaks then appeared, which indicated that the $\mathrm{NO}_{2}^{-}$in $\mathrm{NO}_{2}-\mathrm{AFm}$ had partially been replaced by $\mathrm{Cl}^{-}$chemistry. At the same time, diffraction peaks of $\mathrm{C}$ $\mathrm{S}-\mathrm{H}$ gel, in the cement hydration products, soaked in two kinds of solution, had obviously increased, and no $\mathrm{NO}_{2}{ }^{-} \mathrm{AFm}$ had been generated. Figure 1 shows that that there was a clear competitive adsorption between $\mathrm{Cl}^{-}$and $\mathrm{NO}_{2}{ }^{-}$on the surface of C-S-H gel when $\mathrm{Cl}^{-}$entered the cement paste and competed with $\mathrm{NO}_{2}{ }^{-}$for adsorption on the surface of C-S-H gel. Due to the limited amount of C-S-H gel formation, the

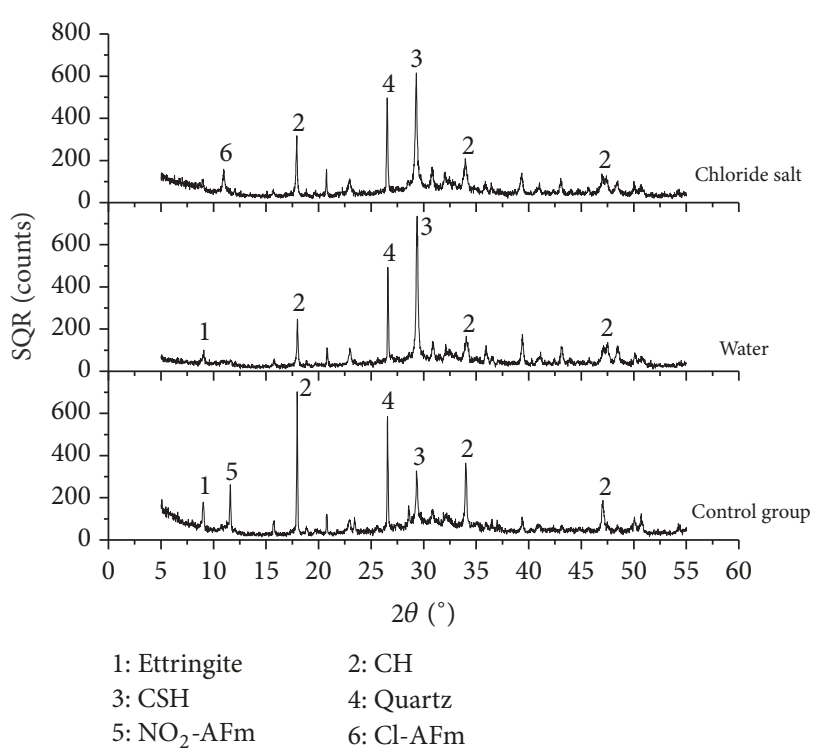

FIGURE 2: XRD of cement paste with $1.0 \% \mathrm{NO}_{2}{ }^{-}$.

infiltration of $\mathrm{Cl}^{-}$lowered the physical adsorption of $\mathrm{NO}_{2}{ }^{-}$, resulting in a relative increase of $\mathrm{NO}_{2}{ }^{-}$in the pore solution.

3.2. Effect of Chloride Erosion Depth on Free $\mathrm{NO}_{2}^{-}$Concentration. Figures 4-6 show the curves of the free-form $\mathrm{NO}_{2}{ }^{-}$ concentration with erosion depth in cement paste specimens, with water-to-cement ratios of $0.3,0.4$, and 0.5 , respectively, in $\mathrm{NaCl}$ solution.

As can be seen from Figures 4-6, the free $\mathrm{NO}_{2}{ }^{-}$concentration decreased with increasing erosion depth. The freeform $\mathrm{NO}_{2}{ }^{-}$concentration on the erosion surface of the 


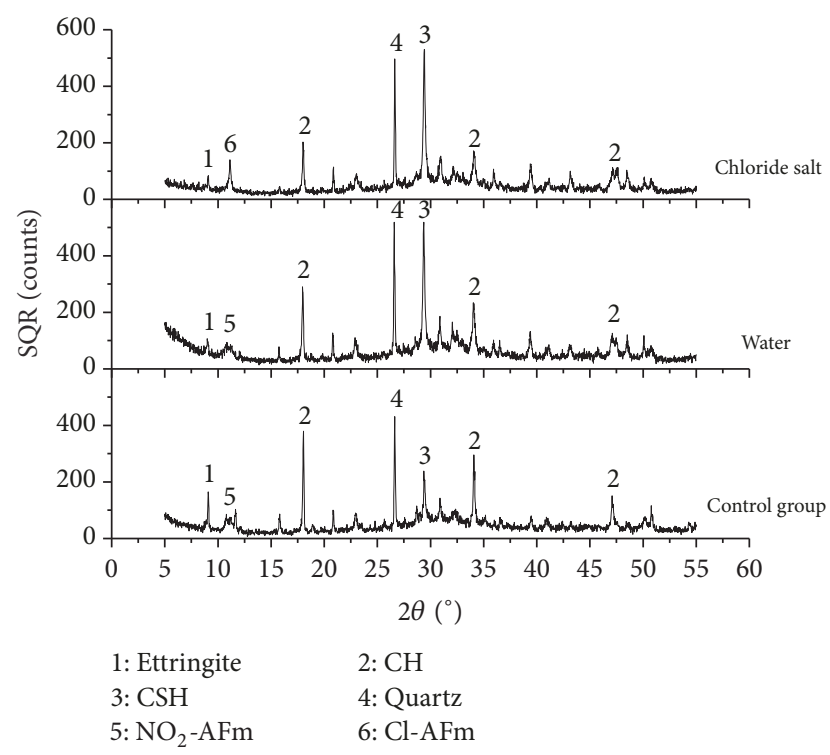

FIgURE 3: XRD of cement paste with 2.0\% $\mathrm{NO}_{2}{ }^{-}$.

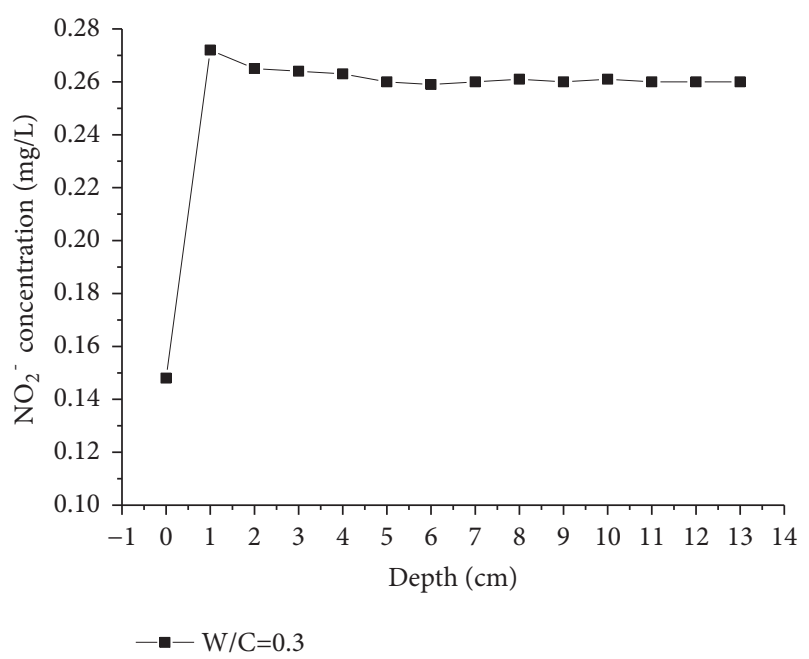

Figure 4: $\mathrm{NO}_{2}{ }^{-}$concentration under $\mathrm{Cl}^{-}$attack (w/c=0.3).

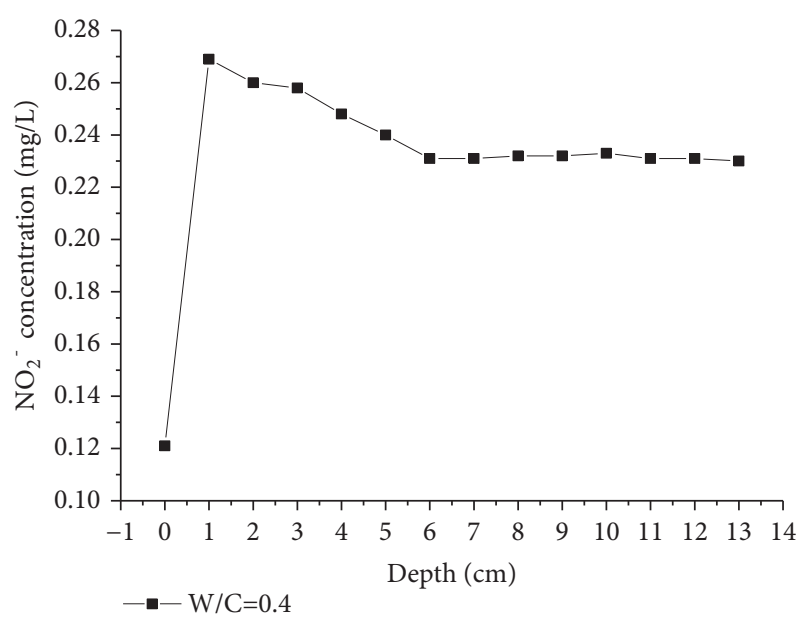

Figure 5: $\mathrm{NO}_{2}{ }^{-}$concentration under $\mathrm{Cl}^{-}$attack $(w / c=0.4)$.

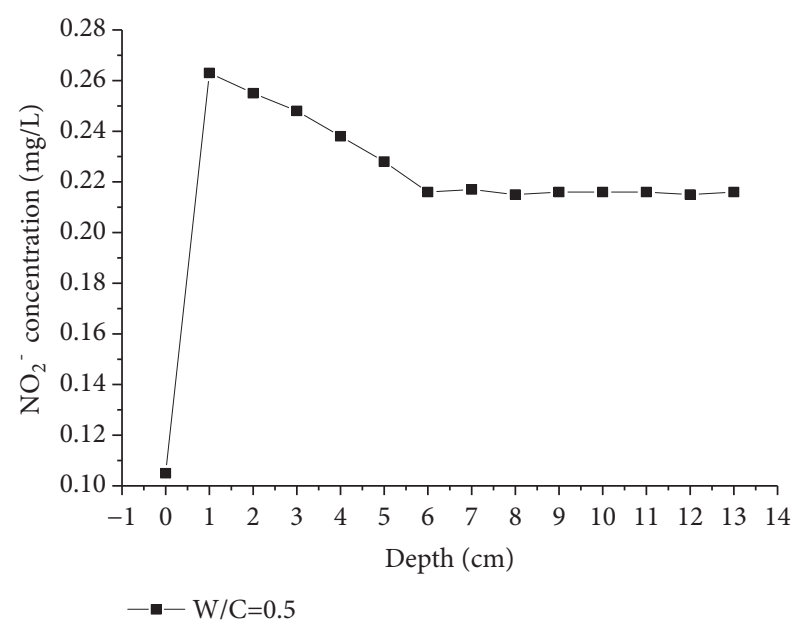

Figure 6: $\mathrm{NO}_{2}{ }^{-}$concentration under $\mathrm{Cl}^{-}$attack $(\mathrm{w} / \mathrm{c}=0.5)$.

cement paste specimens (depth $0 \mathrm{~mm}$ from the erosion surface) was the lowest, far lower than the $\mathrm{NO}_{2}{ }^{-}$concentration inside the cement paste specimens, reached highest value at a distance of $10 \mathrm{~mm}$ from the erosion surface, and achieved a steady state of $80 \mathrm{~mm}$. It was considered that there was a large amount of dissolution of $\mathrm{NO}_{2}{ }^{-}$at the erosion surface. However, in the interior of the cement paste, the content of $\mathrm{NO}_{2}{ }^{-}$dissolution was much lower, so the concentration of free-form $\mathrm{NO}_{2}{ }^{-}$ions on the surface of the test piece was the lowest. As erosion time increased, $\mathrm{Cl}^{-}$diffused into the cement paste specimens, which effected the chloride ion concentration. On the one hand, $\mathrm{Cl}^{-}$displaced $\mathrm{NO}_{2}{ }^{-}$ in the hydration product of $\mathrm{NO}_{2}{ }^{-} \mathrm{AFm}$ to form Friedel's salt, which, relatively, reduced the formation of $\mathrm{NO}_{2}{ }^{-} \mathrm{AFm}$. On the other hand, it competed with $\mathrm{NO}_{2}{ }^{-}$to be adsorbed into the surface of calcium silicate hydrate gel (C-S-H). The greater the $\mathrm{Cl}^{-}$concentration, the greater the concentration of free-form $\mathrm{NO}_{2}{ }^{-}$. At a distance of $10 \mathrm{~mm}$ from the erosion surface, a large amount of $\mathrm{Cl}^{-}$accumulated due to diffusion, so the corresponding free-form $\mathrm{NO}_{2}{ }^{-}$concentration also reached the maximum at this position. At the same time, it can be seen from Figures 4-6 that as the water-to-cement ratio increased, the free-form $\mathrm{NO}_{2}{ }^{-}$concentration inside the cement specimens decreased with the erosion depth. This is because the greater the water-to-cement ratio is, the more the complete hydration within the paste will result in more $\mathrm{C}-\mathrm{S}-\mathrm{H}$. However, at the same time, the greater the porosity of the paste, the faster the migration of $\mathrm{Cl}^{-}$within the paste. The substitution effect of $\mathrm{Cl}^{-}$and the physical adsorption capacity of C-S-H also increased, as did the free-form $\mathrm{NO}_{2}{ }^{-}$ concentration in the paste.

Figure 7 shows the SEM image of cement paste specimens without $\mathrm{NO}_{2}{ }^{-}$, and Figure 8 shows the SEM image of cement paste specimens with $2 \% \mathrm{NO}_{2}{ }^{-}$. Figure 8 shows that the internal structure of cement paste without $\mathrm{NO}_{2}{ }^{-}$was more compact. The surface of cement stone was surrounded by hydration products. These were intertwined and filled the holes in the cement slurry. At the same time, a large amount of granular material was attached to the surface of 


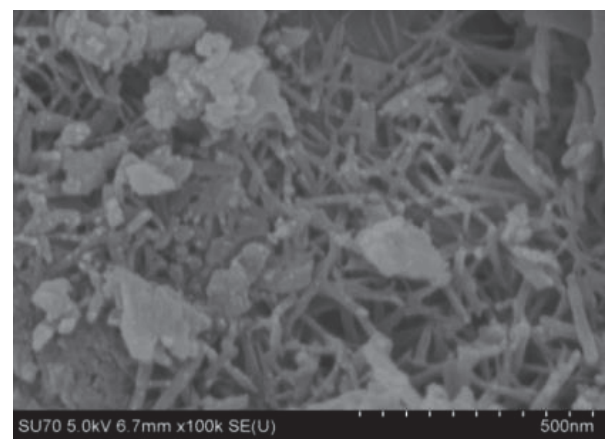

Figure 7: SEM of cement paste without $\mathrm{NO}_{2}{ }^{-}$.

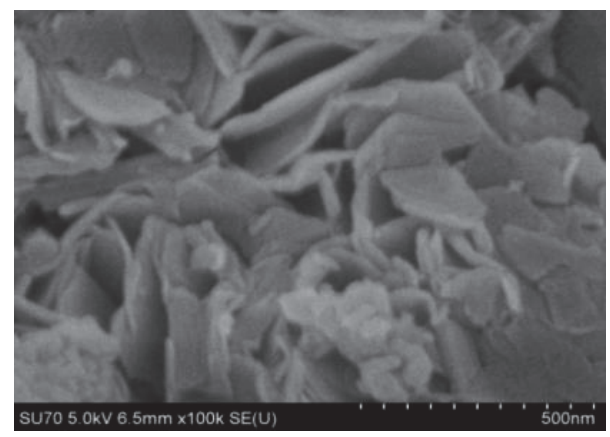

FIGURE 8: SEM of cement paste mixed with $2 \% \mathrm{NO}_{2}{ }^{-}$.

the cement slurry, and large amounts of acicular ettringite crystals and irregular plate crystals were found. The cement paste specimens with $\mathrm{NO}_{2}^{-}$were looser specimens: there were more pores between the crystals and a large number of petal-shaped crystals at the surface. With pure cement paste, however, there were none of these petal-like crystals, from which it can be inferred that this material may be a form of $\mathrm{NO}_{2}$-AFm crystals. At the same time, under the action of aqueous solution and chloride salt solution, hydration of cement matrix was promoted, and the internal structure became more compact. The diffusion of $\mathrm{Cl}^{-}$slowed down with the increase of soaking time and produced a weakening of the competition with the $\mathrm{NO}_{2}{ }^{-}$relationship.

\section{Conclusions}

In this work, the effect of chloride ion on nitrite was investigated using chemical quantitative analysis and microanalysis method. The following conclusions were reached:

(1) The larger amount of free $\mathrm{NO}_{2}{ }^{-}$in the cement paste under chloride salt attack than that when it is soaked in aqueous solution was mainly due to the competitive adsorption of $\mathrm{NO}_{2}{ }^{-}$at the surface of C-S-H and the chemical substitution of $\mathrm{Cl}^{-}$for $\mathrm{NO}_{2}-\mathrm{AFm}$.

(2) Both the aqueous solution and the chloride salt solution promoted the hydration of the cement matrix and made the internal structure more compact. The diffusion of $\mathrm{Cl}^{-}$slowed down with the increase of soaking time and weakened the competition with $\mathrm{NO}_{2}{ }^{-}$.
(3) The cement paste affected by chloride salt had the lowest $\mathrm{NO}_{2}{ }^{-}$concentration on the surface of erosion, and the $\mathrm{NO}_{2}{ }^{-}$concentration reached the highest value at $10 \mathrm{~mm}$ from the erosion surface. As the depth from the erosion surface deepened, the concentration of $\mathrm{NO}_{2}{ }^{-}$trended downwards.

\section{Data Availability}

The data used to support the findings of this study are available from the corresponding author upon request.

\section{Conflicts of Interest}

The authors declare that there are no conflicts of interest regarding the publication of this paper.

\section{Acknowledgments}

This work was sponsored by the National Natural Science Foundation of China $(51478227,51778302)$ and by K.C. Wong Magna Fund in Ningbo University.

\section{References}

[1] I. Fayala, L. Dhouibi, X. R. Nóvoa, and M. Ben Ouezdou, "Effect of inhibitors on the corrosion of galvanized steel and on mortar properties," Cement and Concrete Composites, vol. 35, no. 1, pp. 181-189, 2013.

[2] E. Rakanta, T. Zafeiropoulou, and G. Batis, "Corrosion protection of steel with DMEA-based organic inhibitor," Construction and Building Materials, vol. 44, pp. 507-513, 2013.

[3] C. M. Goulart, A. Esteves-Souza, C. A. Martinez-Huitle, C. J. F. Rodrigues, M. A. M. Maciel, and A. Echevarria, "Experimental and theoretical evaluation of semicarbazones and thiosemicarbazones as organic corrosion inhibitors," Corrosion Science, vol. 67, pp. 281-291, 2013.

[4] J. Shi and W. Sun, "Recent research on steel corrosion in concrete," Journal of the Chinese Ceramic Society, vol. 38, no. 9, pp. 1753-1764, 2010.

[5] L. Luo, A. Adriaens, A. Elia, and G. De Schutter, "Influence of corrosion inhibitors on the Stern-Geary constant in simulated cement pore solutions," Journal of the Chinese Ceramic Society, vol. 42, no. 5, pp. 574-578, 2014.

[6] J. O. Okeniyi, O. A. Omotosho, O. O. Ajayi, and C. A. Loto, "Effect of potassium-chromate and sodium-nitrite on concrete steel-rebar degradation in sulphate and saline media," Construction and Building Materials, vol. 50, pp. 448-456, 2014.

[7] Y.-B. Gao, J. Hu, and Q. Liu, "Application and prospects of corrosion inhibitors for reinforcing steel," Journal of Xiamen University, vol. 54, no. 5, pp. 713-720, 2015.

[8] W. Shi, T.-Z. Wang, Z.-H. Dong, and X.-P. Guo, "Application of wire beam electrode technique to investigate the migrating behavior of corrosion inhibitors in mortar," Construction and Building Materials, vol. 134, pp. 167-175, 2017.

[9] J.-Z. Liu, F. Xing, and Z.-M. He, "Critical mole ratios of nitrite and chloride in reinforced concrete," The Journal of the Chinese Ceramic Society, vol. 38, no. 4, pp. 615-620, 2010.

[10] J. Tritthart and P. F. G. Banfill, "Nitrite binding in cement," Cement and Concrete Research, vol. 31, no. 7, pp. 1093-1100, 2001. 
[11] Z. Cao, Inhibitory effect of nitrite ion on steel bar corrosion, Yangzhou University, 2011.

[12] M. B. Valcarce and M. Vázquez, "Carbon steel passivity examined in solutions with a low degree of carbonation: the effect of chloride and nitrite ions," Materials Chemistry and Physics, vol. 115, no. 1, pp. 313-321, 2009.

[13] J.-Z. Liu, W. Sun, Z.-M. He et al., "Corrosion inhibition of nitrite salt in existing reinforced concrete structures," Journal of The Chinese Ceramic Society, vol. 42, no. 5, pp. 607-612, 2014.

[14] M.-S. Chen, C.-T. Sun, and J.-F. Yu, "Mechanism of corrosion inhibitor in concrete corrosion resistant," Concrete, vol. 6, pp. 80-83, 2015.

[15] S. Tang, "Influence of calcium nitrite on passive films of rebar in simulated concrete pore solution," Materials Protection, vol. 50, no. 8, pp. 28-31, 2017.

[16] B. B. Hope and A. K. C. Ip, "Corrosion inhibitors for use in concrete," ACI Materials Journal, vol. 86, no. 6, pp. 602-608, 1989.

[17] H. S. Wong, Y. X. Zhao, A. R. Karimi, N. R. Buenfeld, and W. L. Jin, "On the penetration of corrosion products from reinforcing steel into concrete due to chloride-induced corrosion," Corrosion Science, vol. 52, no. 7, pp. 2469-2480, 2010.

[18] L. Yohai, W. Schreiner, M. B. Valcarce, and M. Vázquez, "Inhibiting steel corrosion in simulated concrete with low phosphate to chloride ratios," Journal of The Electrochemical Society, vol. 163, no. 13, pp. C729-C737, 2016.

[19] X.-G. Wang, C.-J. Shi, F.-Q. He et al., "Chloride binding and its effects on microstructure of cement-based materials," Journal of The Chinese Ceramic Society, vol. 41, no. 2, pp. 187-192, 2013.

[20] K. Y. Ann, H. S. Jung, H. S. Kim, S. S. Kim, and H. Y. Moon, "Effect of calcium nitrite-based corrosion inhibitor in preventing corrosion of embedded steel in concrete," Cement and Concrete Research, vol. 36, no. 3, pp. 530-535, 2006.

[21] J. Yao, Q. Kong, H. Zhu, Y. Long, and D. Shen, "Adsorption characteristics of nitrite on Friedel's salt under the landfill circumstance," Chemical Engineering Journal, vol. 254, pp. 479485, 2014.

[22] G. Paul, E. Boccaleri, L. Buzzi, F. Canonico, and D. Gastaldi, "Friedel's salt formation in sulfoaluminate cements: A combined XRD and 27Al MAS NMR study," Cement and Concrete Research, vol. 67, pp. 93-94, 2015.

[23] H. Verbruggen, H. Terryn, and I. De Graeve, "Inhibitor evaluation in different simulated concrete pore solution for the protection of steel rebars," Construction and Building Materials, vol. 124, pp. 887-896, 2016. 


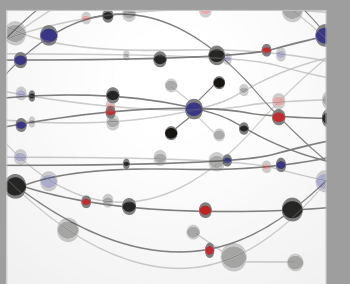

The Scientific World Journal
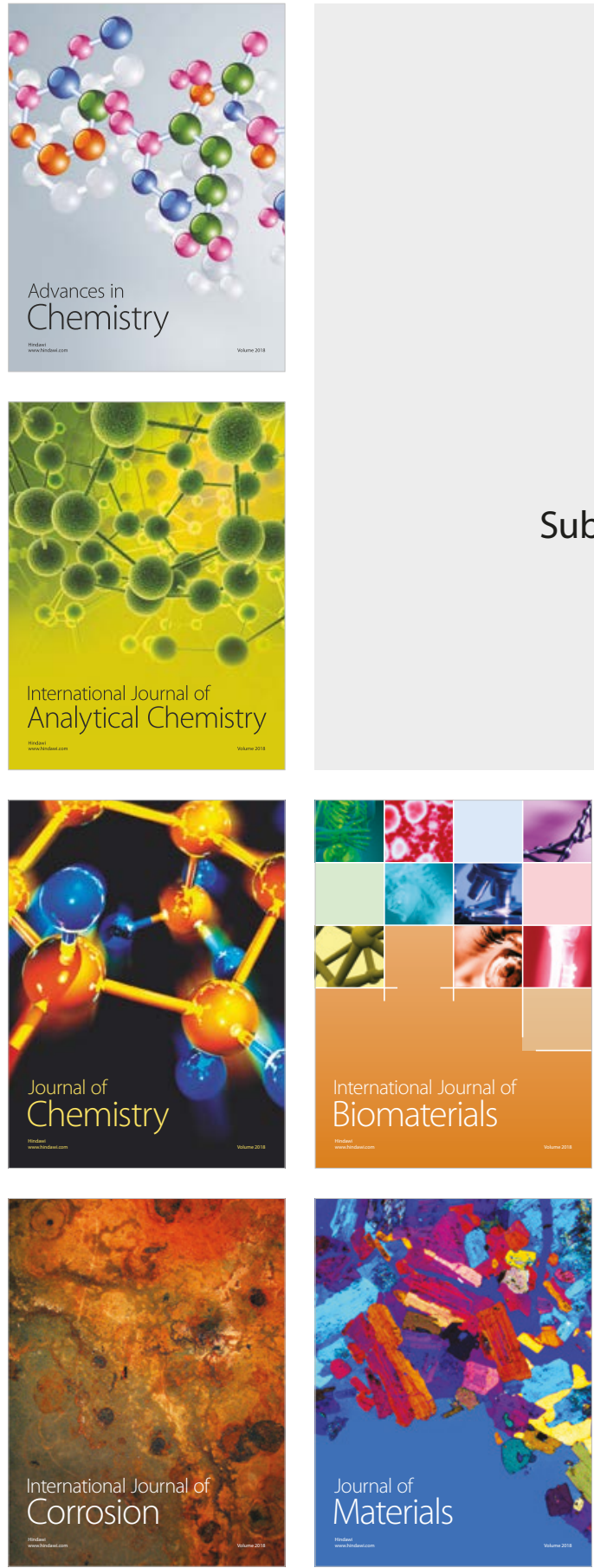

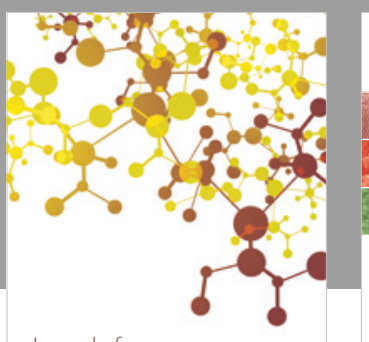

Journal of

Applied Chemistry
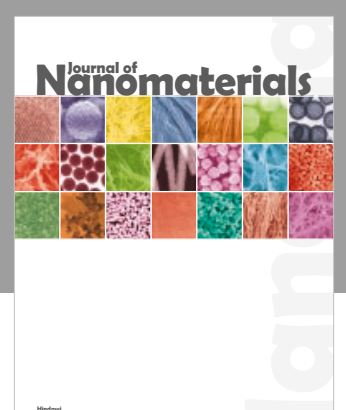

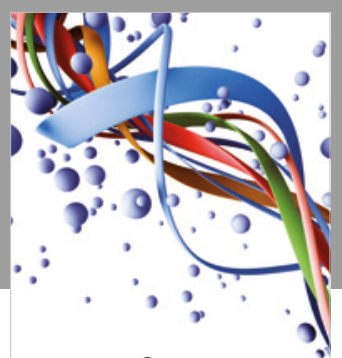

Scientifica

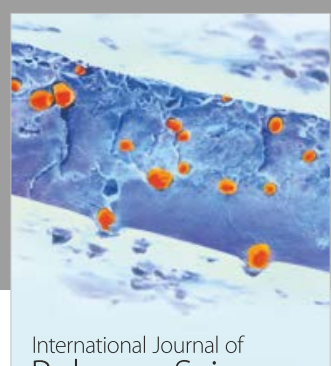

Polymer Science

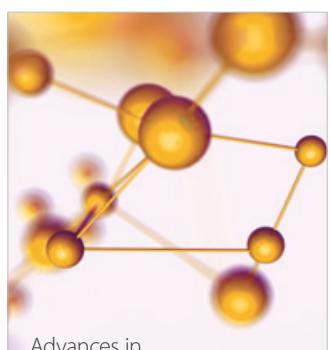

Physical Chemistry
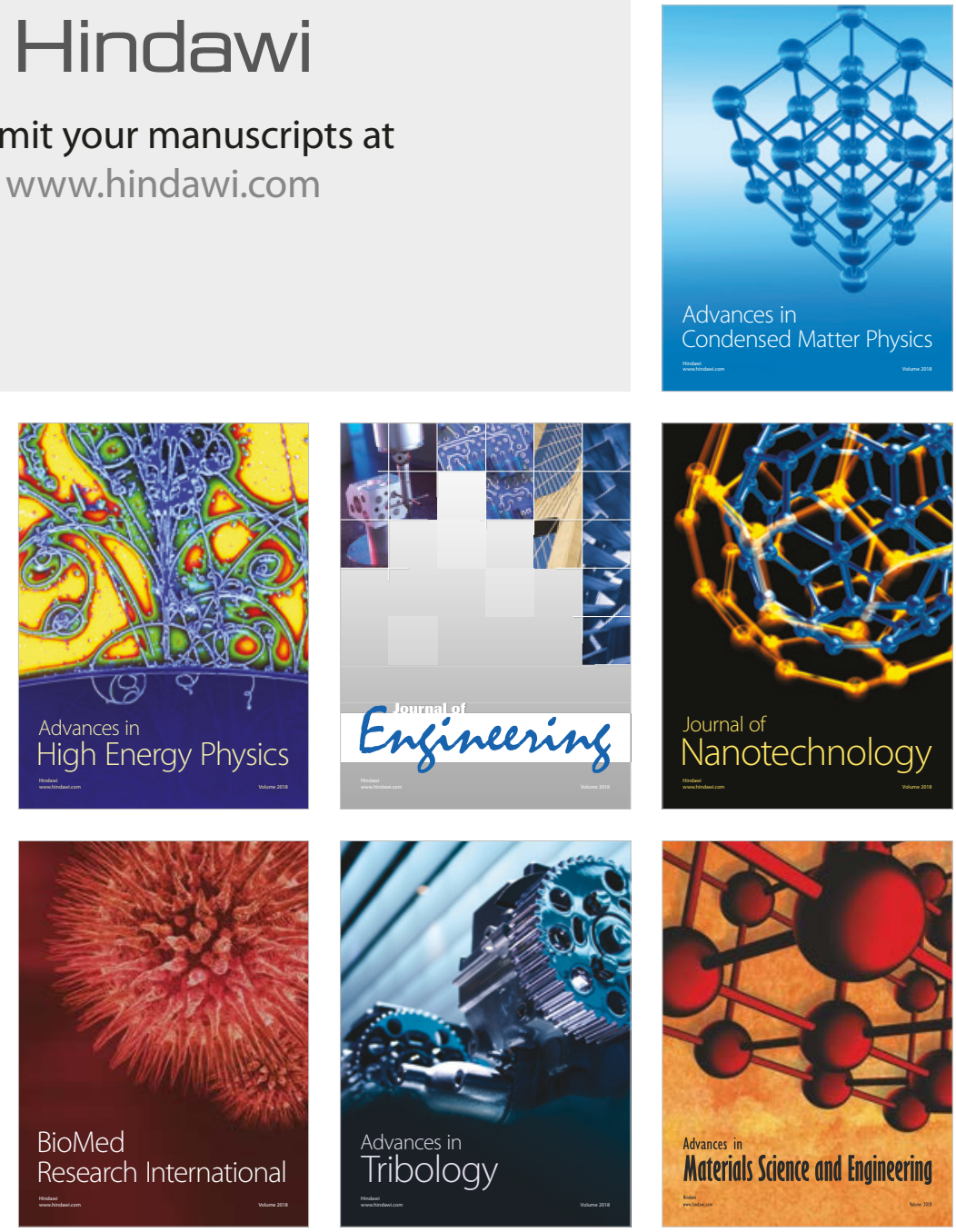